\title{
INFLUÊNCIA DO PORTA-ENXERTO NO COMPORTAMENTO FISIOLÓGICO DE MU- DAS DE CAJUEIRO (Anacardium occidentale L.) SUBMETIDAS A ESTRESSES ${ }^{1}$
}

\author{
NILSON NOGUEIRA MATOS², ANTONIO CAVALCANTI TEXEIRA JUNIOR ${ }^{3}$, JOAQUIM ALBENÍSIO GOMES DA \\ SILVEIRA ${ }^{4}$
}

\begin{abstract}
RESUMO-O uso de mudas enxertadas uniformiza o crescimento de plantas e antecipa o início da produção. Os porta-enxertos regulam aspectos, como taxa fotossintética e relações hídricas das mudas, e distúrbios sobre os mesmos afetam o vigor geral das mudas. Este trabalho objetivou comparar os níveis de resistência dos porta-enxertos CCP06 e CCP09, e das mudas enxertadas CCP76/06 e CCP76/09, submetidas a estresses hídrico e salino, através de algumas características bioquímicas e biofísicas. A comparação entre as mudas CCP76/06 e CCP76/09 mostrou comportamentos diferentes. As mudas CCP76/6 reproduziram o comportamento de abertura estomática do porta-enxerto CCP06, que foi mais resistente aos efeitos dos estresses hídrico e salino do que o CCP09. Portanto, deve ter propiciado uma melhor adaptação ao enxerto CCP76/06 sob aqueles tipos de estresse. Alguns mecanismos de controle do porta-enxerto na absorção de íons e trocas gasosas são também discutidos.
\end{abstract}

Termos para indexação: estresse hídrico, estresse salino, plântula.

\section{INFLUENCE OF ROOTSTOCK ON PHYSIOLOGYCAL BEHAVIOR OF GRAFTED CASHEW NUT TREE (Anacardium occidentale L.) UNDER TWO STRESS CONDITIONS ${ }^{1}$}

\begin{abstract}
The use of grated plants increases uniformity and anticipate the yield. Rootstocks regulate photosynthetic and water relations of the plant and any disruptions of their metabolism may affect the plant vigor. This work aimed to compare resistance levels of dwarf cashew tree rootstocks CCP06 and CCP09, and grafted plants CCP76/06 and CCP76/09 to water and saline stresses through biochemical and biophysics characteristics. The comparison among the grafted plants CCP76/06 and CCP76/09 showed different behaviors. The grafted CCP76/06 reproduced the behavior of stomatal opening of the rootstock $\mathrm{CP} 06$, which was more resistant to the effects of the water and saline stresses than the CCP9 and, therefore, it should have a better adaptation to CCP76/6 under those stresses. The preponderant participation of the rootstock in the regulation of the íons absorption and gas exchanges in dwarf cashew nut tree are also discussed.
\end{abstract}

Index terms: Water stress, salinity stress, cashew seedlings.

\section{INTRODUÇÃO}

A salinização é indesejável à agricultura moderna e, atualmente, $20 \%$ das terras cultivadas, e aproximadamente metade das irrigadas, são afetadas por esse problema. Altas concentrações de sais causam desbalanceamento iônico e maior pressão osmótica nas plantas. Por outro lado, a falta de água tem sido a força seletiva mais pronunciada na evolução das plantas, portanto sua distribuição espacial e produtividade dependem da habilidade das mesmas em lidarem com o déficit hídrico (Hanson \& Hitz, 1982).

Drásticas alterações em íons e suprimento hídrico levam a perda de homeóstase (estabilidade interna do organismo) celular, causando prejuízos a níveis moleculares, suspensão do crescimento e até mesmo a morte. Estes efeitos provocam alterações nas características biofísicas e bioquímicas do processo metabólico, ensejando ajustes na tentativa de estabilização, em suas funções vitais.

Em geral, a natureza de regulação homeostática nos estresses das plantas é semelhante geneticamente (Jian-Kang Zhu, 2001). O efeito dos estresses hídrico e salino, na fisiologia dos porta-enxertos e das mudas de cajueiro, apresenta sequiências de desenvolvimento e progressão bastante diferenciadas, embora produzam efeitos prejudiciais semelhantes, a intervalos de tempo aproximados.

O uso de mudas enxertadas uniformiza o crescimento de plantas e antecipa o início da produção. Diferentes combinações de portaenxertos e copa, resultam em alterações fisiológicas nas mudas, tais como as relações hídricas e trocas gasosas (Castle et al., 1989) que podem originar melhores adaptações a diferentes condições ambientais.

Qualquer incremento no grau de resistência das plantas aos estresses pode evitar perdas da produção em áreas semi-áridas ou estabilizálas em regiões sujeitas a condições ambientais adversas ocasionais.

O trabalho objetivou comparar os níveis de resistência dos porta-enxertos CCP06 e CCP09, e das mudas enxertadas CCP76/06 e CCP76/09, submetidas a estresse hídrico ou salino, sob condições de casa de vegetação, através de algumas características bioquímicas e biofísicas.

\section{MATERIAL EMÉTODOS}

As plântulas (seedling) de cajueiro dos materiais CCP06 (clone de cajueiro de Pacajus 06) e CCP09 (clone de cajueiro de Pacajus 09), originadas de sementes, e as mudas enxertadas CCP76/06 e 76/09 foram oriundas do jardim clonal da estação experimental de Pacajus-CE, da Embrapa Agroindústria Tropical. As mudas foram desenvolvidas em tubetes de $288 \mathrm{~cm}^{3}$ com substrato de vermiculita e submetidas a estresse hídrico pela suspensão da rega diária e a estresse salino pelo contato contínuo com solução salina de $200 \mathrm{mM}$ de $\mathrm{NaCl}$, aos 35 e 120 dias após a germinação (DAG), respectivamente, por 4 dias consecutivos. Inicialmente, antes dos estresses, as plântulas e mudas cresceram por 15 dias, sob capacidade de campo, por ascensão capilar, com solução nutritiva de Hogland modificada nas seguintes proporções: $\left[\mathrm{NO}_{3}^{-}\right]: 4 ; \mathrm{NH}_{4} \mathrm{Cl}: 1$; $\mathrm{P}: 0.5 ; \mathrm{K}^{+}: 3 ; \mathrm{Mg}^{+2}: 0.5 ; \mathrm{S}: 0.5 ; \mathrm{Ca}^{+2}: 1$. Essa condição foi mantida nas plantas-controle.

Utilizou-se delineamento inteiramente ao acaso, com três tratamentos (controle, estresse hídrico e estresse salino) e com três repetições de 25 plântulas por parcela, com colheitas em diferentes tempos de tratamento $(1 ; 2 ; 4 ; 6$ e 16 dias). A comparação entre os tratamentos foi realizada por análise de variância e as médias pelo teste de Tukey, ao nível de 5\% de probabilidade.

Todas as determinações biofísicas e bioquímicas foram realizadas no segundo par de folhas totalmente expandidas. As medições de condutância estomática $(\mathrm{Ce})$, temperatura $(\mathrm{T})$, radiação fotossinteticamente ativa - PAR, e umidade relativa (UR) foram obtidas às $10 \mathrm{~h}$, utilizando o porômetro de equilíbrio dinâmico Li-Cor 1600. O potencial hídrico $\left(\Psi_{\mathrm{w}}\right)$ foi medido subseqüentemente através do corte transversal do caule com medição da pressão do xilema com uso da bomba de Scholander. A determinação da massa úmida da parte aérea foi

\footnotetext{
1 (Trabalho 150/2001). Recebido: 24/09/2001; Aceito para publicação: 11/12/2002.

${ }^{2} \mathrm{Agr}^{\circ}$ M.Sc. Bolsista CNPq. Av. J. Albuquerque, ed. C.Millet-GDS/C. Viva, Calhau S. Luis-MA nilson30@ aol.com.br.

${ }_{3}^{3}$ EMBRAPA/CNPAT- Rua Dra. Sara Mesquita 2270, Cep 60511-110. CE e-mail teixeira@ cnpat.embrapa.br.

${ }^{4}$ Prof. Dr. Universidade Federal. do Ceará - UFC. CP 6020 Bolsista de pesquisa do CNPq.e-mail: silveira@ufc.br.
} 
obtida por pesagem da porção destacada à altura do coleto. Para a determinação da atividade de redutase de nitrato (ARN) in vivo, utilizou-se do método de Hagerman \& Hucklesby (1971). A concentração de prolina livre (Pro), nitrato $\left(\mathrm{NO}_{3}\right), \mathrm{Na}^{+}$e $\mathrm{K}^{+}$na folha e proteínas solúveis foi determinada pelos métodos de Bates et al. (1973) e Cataldo et al. (1975) e a digestão nitroperclórica de Sarruge \& Haag (1974) e Bradford (1976), respectivamente.

\section{RESULTADOS E DISCUSSÃO}

As alterações menos pronunciadas de algumas características bioquímicas nos porta-enxertos CCP06 e CCP09, quando submetidos aos estresses hídrico e salino, referem-se ao status hídrico das plantas (Tabela 1). Verificou-se que os estresses salino e hídrico se alteraram com o tempo (Tabela 2), intensificando os efeitos da condutância estomática (Ce), da taxa de transpiração (T), da massa úmida (Um), da pressão osmótica $(\Psi \mathrm{w})$ e da atividade de redutase de nitrato (ARN).

A atividade da enzima redutase de nitrato é estreitamente controlada por flutuações ambientais, e normalmente induzida pela concentração de $\mathrm{NO}_{3}^{-}$, seu substrato. Porém, esta não foi afetada pelo decréscimo ou acréscimo da concentração de $\mathrm{NO}_{3}^{-}$, devido aos estresses impostos. A RNA dos porta-enxertos CCP06 e CCP09 apresentou baixa sensibilidade (decréscimo) aos estresses hídrico $(83,3 \% ; 55,5 \%)$ e salino $(108 \%$, $92,5 \%)$ em percentual do controle, respectivamente. Isto pode ser devido à predominância da forma RN constitutiva, a qual não é induzida por $\mathrm{NO}_{3}^{-}$. Esta forma da enzima pode conferir proteção às plantas estressadas (FERRARIO-MÉRY et al., 1998).

TABELA 1-Efeitos dos estresses hídricos e salino, durante 4 dias, sobre as variáveis relacionadas às relações hídricas na planta, ARN e acúmulo de solutos nas folhas dos porta-enxertos CCP06 e CCP09 e em mudas enxertadas de CCP 76/06 e CCP76/09. Fortaleza-CE, 2001.

\begin{tabular}{|c|c|c|c|c|c|c|c|c|c|c|}
\hline Tratamentos & Materiais & $\mathrm{ARN}^{1}$ & $\mathrm{Pro}^{2}$ & $\mathrm{Mu}-\mathrm{p}^{3}$ & $\mathrm{~K}^{4}$ & $\mathrm{NO}_{3}{ }^{5}$ & $\mathrm{Na}^{6}$ & $\mathrm{Ce}^{7}$ & $\mathrm{~T}^{8}$ & $\Psi w^{9}$ \\
\hline \multirow{4}{*}{ Controle } & CP 06 & $0,24^{2 \mathrm{~A}(10)}$ & $1,85^{\mathrm{a}}$ & $7,1^{\mathrm{bC}}$ & $176^{\text {aA }}$ & $171,6^{\mathrm{a}}$ & $43,2^{\mathrm{aB}}$ & $1,24^{\mathrm{aA}}$ & $5,51^{\mathrm{aAB}}$ & $0,3^{\mathrm{aA}}$ \\
\hline & CP 09 & $0,27^{\mathrm{aA}}$ & $0,65^{\mathrm{a}}$ & $9,2^{\mathrm{aB}}$ & $169,6^{\mathrm{aA}}$ & $136,5^{\text {ab }}$ & $64,8^{\mathrm{bc}}$ & $0,34^{\mathrm{bBC}}$ & $3,14^{2 C}$ & $0,18^{\mathrm{aA}}$ \\
\hline & CP 76/06 & $0,174^{\mathrm{bB}}$ & ND & $16,2^{\mathrm{aA}}$ & $103^{\mathrm{B}}$ & ND & $28^{\mathrm{A}}$ & $0,59^{\mathrm{aB}}$ & $6,41^{\text {aA }}$ & $0,2^{\mathrm{aA}}$ \\
\hline & CР 76/09 & $0,22^{\mathrm{aA}}$ & ND & $18,5^{\text {aA }}$ & ND & ND & ND & $0,25^{\mathrm{bC}}$ & $4,1^{\mathrm{aB}}$ & $0,35^{\mathrm{aA}}$ \\
\hline \multirow{4}{*}{ Estresse Hídrico } & CP 06 & $0,20^{\mathrm{aB}}$ & $2,33^{\mathrm{a}}$ & $7,2^{\mathrm{aB}}$ & $166,4^{\mathrm{aA}}$ & $54,6^{b}$ & $59,4^{b}$ & $0,22^{\mathrm{aB}}$ & $1,36^{2 \mathrm{C}}$ & $0,5^{\mathrm{aA}}$ \\
\hline & CР 09 & $0,15^{\mathrm{bB}}$ & $27,65^{b}$ & $5,92^{\mathrm{bC}}$ & $169,6^{\mathrm{aA}}$ & $187,85^{a}$ & $70,2^{a}$ & $0,02^{\mathrm{bC}}$ & $0,2^{\mathrm{bD}}$ & $3,6^{\mathrm{bC}}$ \\
\hline & CP 76/06 & $0,523^{\mathrm{aA}}$ & ND & $11,4^{\mathrm{aA}}$ & ND & ND & ND & $0,523^{\mathrm{aA}}$ & $6,86^{\mathrm{aA}}$ & $0,6^{\mathrm{aA}}$ \\
\hline & CP 76/09 & $0,65^{\mathrm{aA}}$ & ND & $11^{\mathrm{aA}}$ & ND & ND & ND & $0,31^{\mathrm{aAB}}$ & $2,8^{\mathrm{bB}}$ & $1,2^{\mathrm{bAB}}$ \\
\hline \multirow{4}{*}{ Estresse Salino } & CP 06 & $0,26^{\mathrm{aB}}$ & $2,64^{\mathrm{a}}$ & $6,5^{\mathrm{aB}}$ & $198,4^{\mathrm{aA}}$ & $83,85^{b}$ & $118,8^{\mathrm{aA}}$ & $0,19^{\mathrm{aB}}$ & $0,95^{2 C}$ & $1,75^{a C}$ \\
\hline & CP 09 & $0,25^{\mathrm{aB}}$ & $8,86^{b}$ & $6,11^{\mathrm{aB}}$ & $192^{\mathrm{aA}}$ & $193,95^{\mathrm{a}}$ & $307,8^{\mathrm{bB}}$ & $0,02^{\mathrm{bC}}$ & $0,2^{\mathrm{bD}}$ & $2,25^{\mathrm{bC}}$ \\
\hline & CP 76/06 & $0,435^{\mathrm{aAB}}$ & ND & $9,85^{\mathrm{aAB}}$ & $84^{\mathrm{B}}$ & ND & $91^{\mathrm{A}}$ & $0,137^{\mathrm{aA}}$ & $2,33^{\mathrm{aB}}$ & $0,35^{\mathrm{aA}}$ \\
\hline & CР 76/09 & $0,5^{\text {aA }}$ & ND & $10,2^{\text {aA }}$ & ND & ND & ND & $0,15^{\text {aA }}$ & $3,2^{\mathrm{aA}}$ & $0,75^{\mathrm{bB}}$ \\
\hline
\end{tabular}

ARN=atividade de redutase de nitrato; Pro = Prolina; $\mathrm{Mu}-\mathrm{p}=$ Material úmido; $\mathrm{K}=$ Potássio; $\mathrm{NO}_{3}=$ Nitrato; $\mathrm{Na}=$ Sódio $;$ Ce $=$ Condutância Estomática $\mathrm{T}=$ Taxa de Transpiração; $\Psi_{\mathrm{w}}=$ Potencial Hídrico

(1) $\mathrm{mmol} \mathrm{NO} 2 / \mathrm{Kg} \mathrm{MS} / \mathrm{h}$; (2) mmol /KgMF; (3) g/planta; (4) mmol/Kg MS; (5) mmol/Kg MS; (6) mmol/Kg MS; (7) cm/s; (8) $\mu \mathrm{mol} . \mathrm{cm}^{2} / \mathrm{s}$; (9) - Mpa.

(10) Médias, dentro dos tratamentos, seguidas por letras maiúsculas nas colunas não diferem entre si, a nível de 5\% de significância, pelo teste de Tukey. Médias, dentre os mateiais, seguidas por letras minúsculas nas colunas não diferem entre si nem entre os tratamentos, a nível de 5\% de significância, pelo teste de Tukey.

TABELA 2-Valores médios em dias referentes a condutância estomática (Ce), taxa de transpiração (T), massa úmida (Mu), potencial hídrico ( $\Psi$ w) e atividade de redutase de nitrato (ARN) sob estresses.

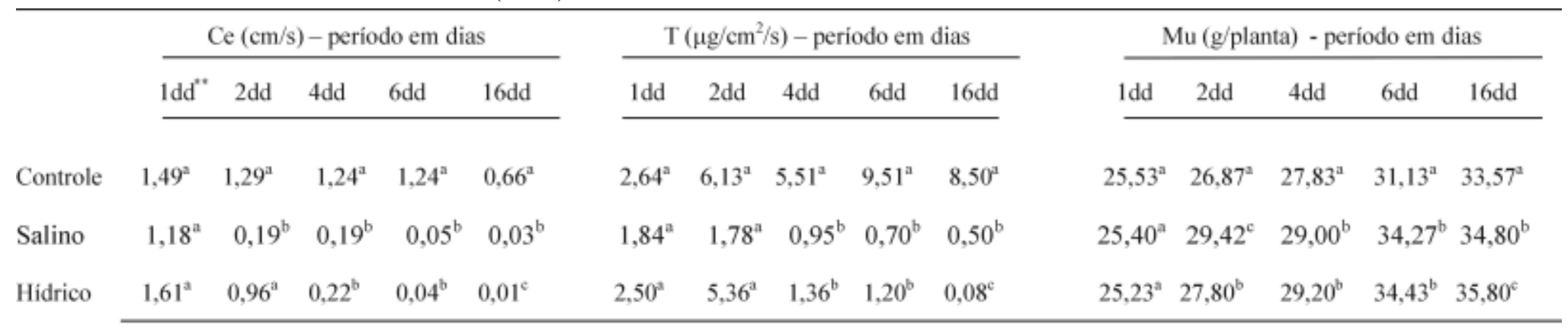

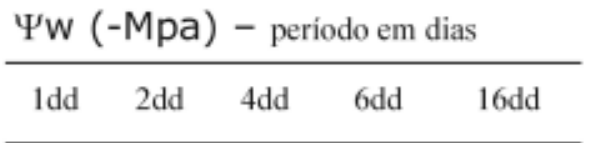

$\mathrm{ARN}(\mathrm{mmolNO} 2 / \mathrm{Kg} \mathrm{MS} / \mathrm{h})$ - período em dias

1dd $\quad 2$ dd $\quad 4$ dd $\quad 6$ dd $\quad 16$ dd

Controle $\quad 0,30^{\mathrm{a}} \quad 0,30^{\mathrm{a}} \quad 0,30^{\mathrm{a}} \quad 0,30^{\mathrm{a}} \quad 0,30^{\mathrm{a}}$

$0,45^{\mathrm{a}} \quad 0,30^{\mathrm{a}} \quad 0,22^{\mathrm{a}} \quad 0,25^{\mathrm{a}} \quad 0,32^{\mathrm{a}}$

Salina $\quad 0,52^{\mathrm{b}} \quad 0,55^{\mathrm{b}} \quad 1,75^{\mathrm{c}} \quad 2,10^{\mathrm{c}} \quad 2,25^{\mathrm{c}}$

$0,50^{\mathrm{a}} \quad 0,56^{\mathrm{a}} \quad 0,26^{\mathrm{a}} \quad 0,22^{\mathrm{a}} \quad 0,07^{\mathrm{b}}$

Hidrico $\quad 0,52^{\mathrm{b}} \quad 0,82^{\mathrm{c}} \quad 1,05^{\mathrm{b}} \quad 1,12^{\mathrm{b}} \quad 1,15^{\mathrm{b}}$

$0,42^{\mathrm{a}} \quad 0,35^{\mathrm{a}} \quad 0,28^{\mathrm{a}} \quad 0,2^{\mathrm{b}} \quad 1,15^{\mathrm{b}}$

- Médias seguidas da mesma letra nas colunas não diferem entre si, pelo teste de Tukey, a 5\%

** $\mathrm{dd}=$ período em dias 
A atividade de redutase de nitrato também pode ter sido relacionada à concentração de prolina nos tecidos. Dentre as diversas funções da prolina, destaca-se a proteção de proteínas contra a desnaturação, eliminação de radicais livres e estabilização do pH celular sob condições de estresses iônico e osmótico (Venekamp, 1989; Silveira et al., 2000). Por outro lado, a acumulação de prolina em folhas de plântulas de cajueiro pode refletir intensos distúrbios metabólicos, principalmente a degradação de proteínas e a senescência induzidas por estresse, conforme demonstrado por Viégas \& Silveira (1999). Desse modo, o aumento abrupto de prolina no material CCP09 de $4253 \%$ sob estresse hídrico, em comparação com o controle, está em consonância com a maior queda percentual da ARN (55,5\%). Isto sugere que a produção de prolina seja mais um indicador dos níveis de estresse nos porta-enxertos (Tabela 1), do que um elemento de proteção (Viégas \& Silveira, 1999; Viégas et al., 1999).

A possibilidade de as plantas atingirem alta produtividade sob estresse salino, está na dependência de uma possível reação positiva a aumentos de pressão osmótica ou a toxidez de íons, como o $\mathrm{Na}^{+}$. O primeiro dano na integridade da membrana celular é ocasionado pela substituição do $\mathrm{K}^{+}$pelo $\mathrm{Na}^{+}$; portanto, a dificuldade apresentada por cada espécie ou a tolerância da membrana em perder $\mathrm{K}^{+}$a maiores concentrações de $\mathrm{Na}^{+}$na solução torna-se fundamental para homeóstase celular (Graham \& Ulrich, 1972). Nas plântulas de cajueiro, ocorreu aumento de $\mathrm{K}^{+}$em ambos porta-enxertos, em contraste com um pronunciado aumento de $\mathrm{Na}^{+}$no CCP09 (476\%) e CCP06 (276\%) em relação ao controle. Porém, houve indício de uma ação restritiva de acúmulo de $\mathrm{Na}^{+}$no material CCP06, por absorção seletiva (Tabela 1). A relação $\mathrm{K} / \mathrm{Na}$ nos materiais estudados mostrou uma redução nos valores de 3,33 no tratamento-controle, para 1,69 no CCP06 e 0,65 no CCP09, com resposta de forma proporcional na abertura estomatal e, por conseguinte, no suprimento hídrico. Verifica-se, assim, uma sinergia entre o efeito de proteção nos níveis de $\mathrm{K}^{+}$e uma maior permeabilidade radicular do material CCP06, originada, talvez, de uma maior concentração de $\mathrm{Ca}^{+2}$ na membrana de suas células radiculares, como descrito por Cramer et al. (1985).

Os resultados da condutância estomática $(\mathrm{Ce})$, transpiração $(\mathrm{T})$ e pressão osmótica $\left(\Psi_{\mathrm{W}}\right)$, analisados conjuntamente, evidenciam a rápida diminuição da $\mathrm{Ce}$ em resposta à deficiência hídrica ou estresse salino, documentada na literatura (Faquhar \& Sharkey, 1982). A variação da transpiração apresentou a mesma tendência de redução em Ce. O comportamento do $\Psi \mathrm{w}$ mostrou resultados também similares com a progressão dos estresses. Porém, com a ocorrência de seca, a permeabilidade da membrana pode ser rompida e o turgor celular impedido, mascarando os resultados. Neste estudo, as plantas submetidas à seca estabilizaram o $\Psi_{\mathrm{w}} \mathrm{em}$ torno de $-1,05 \mathrm{MPa}$ a partir do $4^{\circ}$ dia e apresentaram potenciais menos negativos do que daquelas sob estresse salino, nas quais os valores continuaram a decrescer, devido provavelmente a ajustamento osmótico.

O comportamento estomático apresentou picos de máxima abertura pela manhã e início da tarde com depressão das trocas gasosas ao meio dia, embora o CCP09 tenha mostrado dois picos subsequientes pela manhã (Figuras 1A e 1B). Estes resultados confirmam os obtidos por Ferreira (1992), cujo fechamento estomático foi induzido pelo aumento de $\mathrm{CO}_{2}$ interno, decorrente da maior atividade respiratória em relação à fotossintética, ocasionada pelo aumento de temperatura foliar (Figura 1C). O fechamento estomático evita a ocorrência de danos aos sistemas metabólicos, ajustando-os ao déficit de umidade na planta, resultando em aumento temporário do $\Psi w$ na folha (Larcher, 1987). Este fechamento persiste até após a diminuição da radiação fotossinteticamente ativa ( PAR) no meio da tarde (Figura 1D).
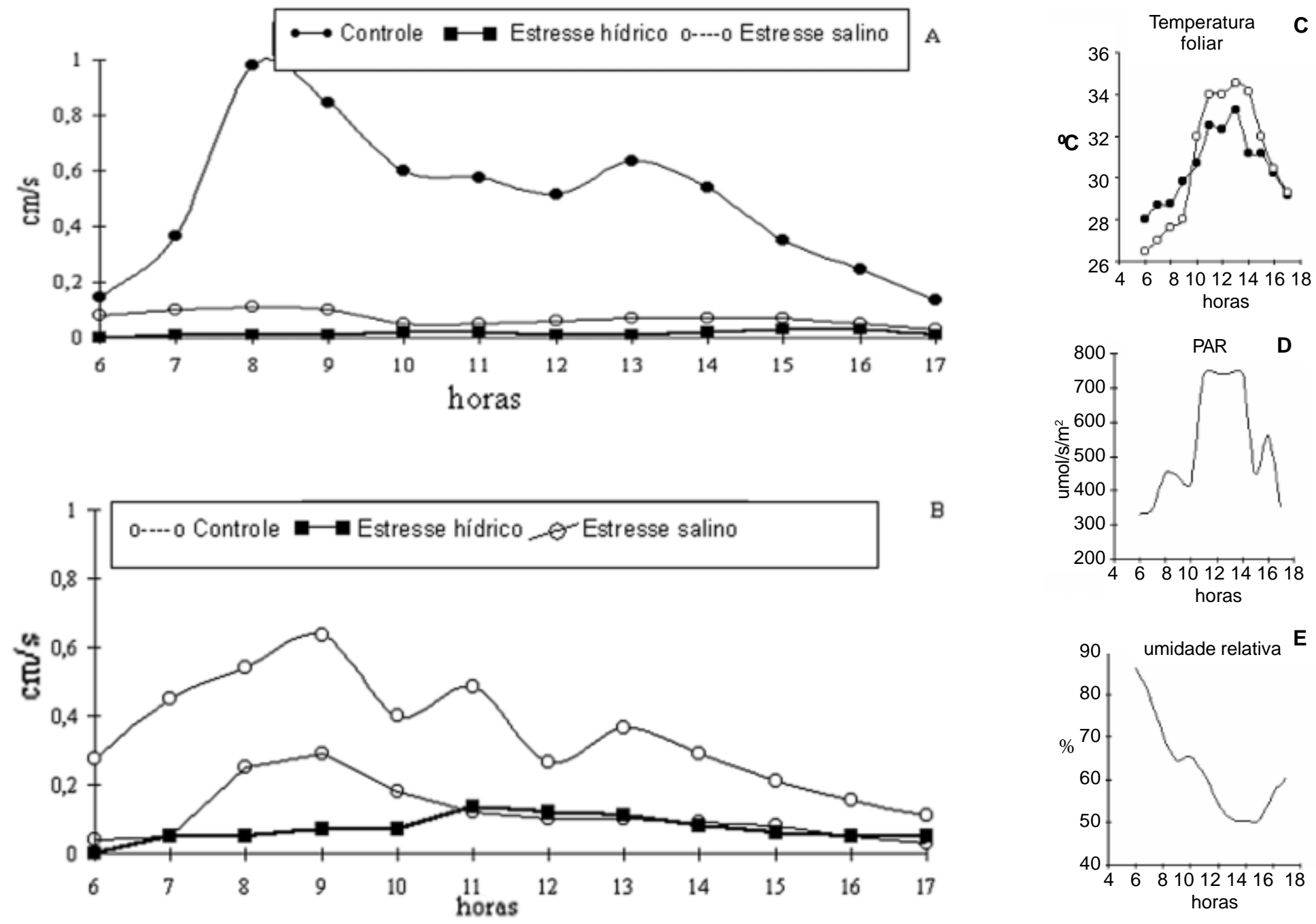

FIGURA 1- Condutância estomática nos porta-enxertos CCP06 (A) e CCP09 (B) de cajueiro-anão submetidos a 6dias de estresse, durante um dia típico (baixa nebulosidade) em Fortaleza-CE, 2001. 
Os estresses hídrico e salino alteram a intensidade e duração característica de abertura e fechamento estomático ao longo do dia. As plantas sem reservas de água abrem os estômatos mais lentamente, reduzindo progressivamente a perda de água durante períodos mais curtos (Figura 1A e 1B). Este resultado foi também encontrado por Tenhunen et al. (1987), em plantas do semi-árido, as quais reduziram, a princípio, a transpiração durante as horas mais quentes do dia. Posteriormente, o pico da tarde é omitido com a progressão dos estresses, e finalmente os estômatos abrem-se em menor grau apenas nas primeiras horas da manhã.

As duas modalidades de estresse induziram respostas semelhantes em ambos os materiais com valores de condutância próximos a zero. A despeito de as plantas sob estresse salino apresentarem valores de condutância inferiores aos do controle, seus padrões de resposta foram semelhantes. No entanto, as plantas submetidas ao estresse hídrico quase não demonstraram resposta em Ce às mudanças ambientais ocorridas ao longo do dia (Figuras 1A e 1B).

A variação da condutância estomática nas mudas oriundas dos porta-enxertos CCP06 e CCP09, ambos enxertados com o material clonal CCP76, é representada na Figura 2. O CCP76/06 apresentou uma resposta semelhante àquela do porta-enxerto CCP06 (Figura 2A), apresentando um máximo de abertura entre 8 e 10h, enquanto o CCP76/09 mostrou resposta diferente do porta-enxerto CCP09 com valores decrescentes ao longo do dia (Figura 2B) e máximo de condutância estomática no início da manhã $6 \mathrm{~h}$.
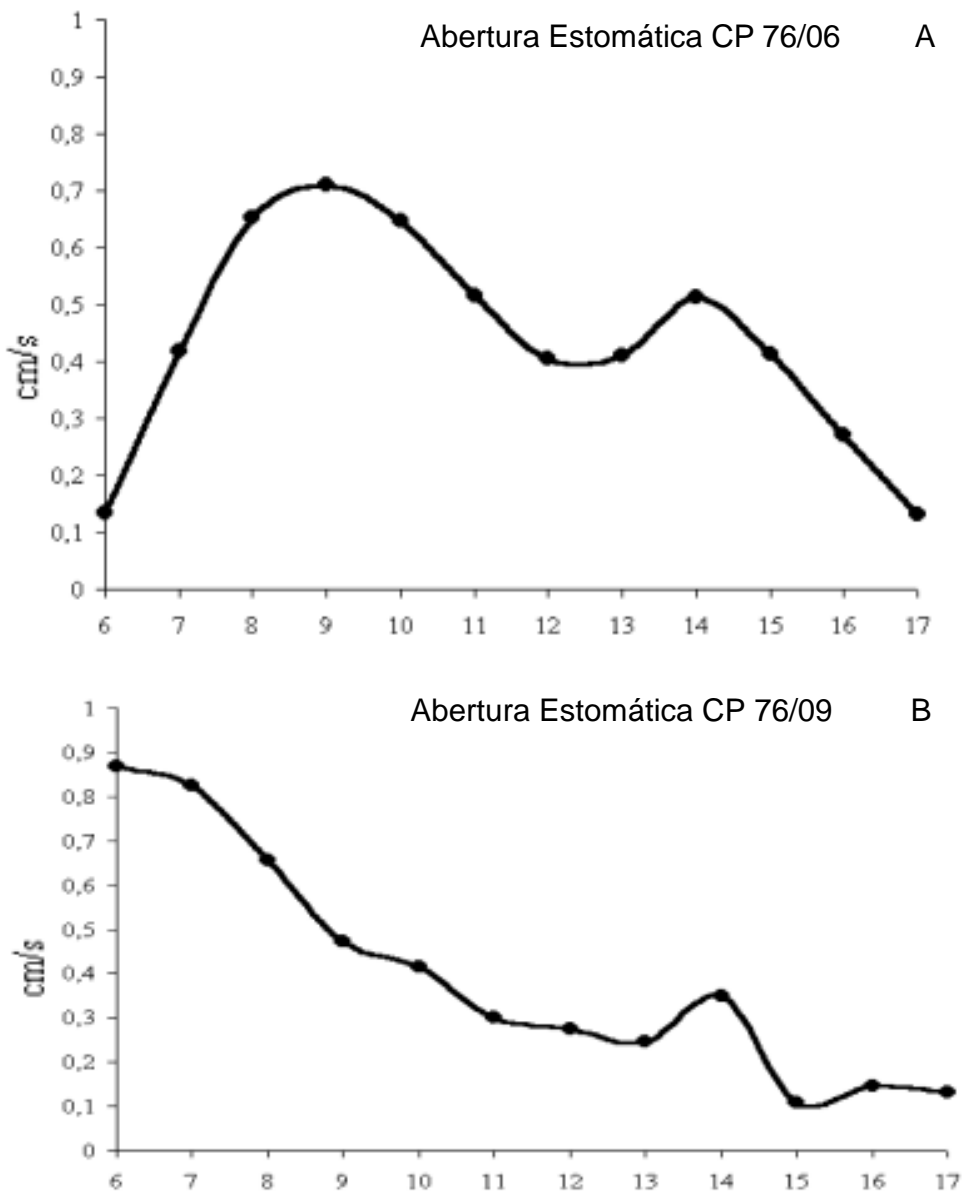

FIGURA 2- Condutância estomática de mudas enxetadas CP76/06 (A) e CP76/09 (B) de cajueiro-anão durante um dia típico (sem nebulosidade) em Fortaleza-CE, 2001.

Quando os porta-enxertos CCP06 e CCP09 cresceram sob condições não estressantes (controle), foi observada maior produção de matéria fresca na parte aérea no CCP09 (9,2 g/planta) em relação ao CCP06 (7,1 g/planta), aos 39 dias após o plantio. Entretanto, após quatro dias de estresses hídrico e salino, a matéria fresca das plantas CCP09 decresceu mais do que no CCP06, com redução para 53\%, 66\% e 75\%, 85\% da matéria fresca obtida dos seus controles, respectivamente. Essa resistência está relacionada aos valores mais elevados em $\mathrm{Ce}=10$ vezes, $\mathrm{da} \mathrm{T}=6$ vezes e o $\varnothing_{\mathrm{W}}=4$ vezes no porta-enxerto CCP06, em relação ao CCP09.

O cajueiro apresenta uma importante característica de resistência aos estresses hídrico e salino, a preservação do meristema apical, que continua a emissão de folhas novas, sadias; esse comportamento é típico de espécies que, preferencialmente, devido à translocação $\mathrm{Na}^{+} \mathrm{de}$ outras partes da planta, acumulam sais nas folhas mais velhas (Lacan \& Duran, 1995).

\section{CONCLUSÕES}

O potencial hídrico $\left(\varnothing_{\mathrm{w}}\right)$ das mudas de cajueiro sob estresse hídrico é maior do que naquelas sob estresse salino, e os porta-enxertos do CCP06 apresentam maior capacidade de ajustamento osmótico em presença de salinidade. Conclui-se que a resistência nas mudas de cajueiro enxertadas com CCP76 é determinada pelas características do portaenxerto, sendo que o CCP06 demonstra vantagens na manutenção do balanço hídrico com melhor ajuste da combinação CCP76/06 às condições de estresses hídrico e salino apresentadas.

\section{REFERÊNCIASBIBLIOGRÁFICAS}

CASTLE, W. S. et al. Rootstocks for florida citrus. Gainsville: Institute of Food and Agricultural Science - University of Florida, 1989. 47 p.

BATES, L. S.; WALDREN, R. P.; TEARE, I. D. Rapid determination of free proline for water stress studies. Plant and soil, Dorchecht, v. 39, p. 205-207,1973.

BRADFORD, M. M. A rapid e sensitive method for the qualitataion of mocrogram quanties of protein utilinzing the principle of protein-dye binding. Anlitic biochemistry, v. 722, P. 248-254, 1976.

CATALDO, D. A.; HAROON, M.; SCHRADER, L. E.; YOUNGS, V. L. Rapid colorimetric determination of nitrate in plant tissue by nitration of salicilic acid. Communication in Soil Science and Plant Analysis, Montreal, n. 6, v. 1, p. 71-80, 1975.

CRAMER, G. R.; LAUCHLI, A.; POLITO, V. S. Displacement of $\mathrm{Ca}^{+2}$ by $\mathrm{Na}^{+}$from the plasmalemma of root cells: a primary response to salt stress. Plant physiology, Bethesda, v. 79, p.207-211, 1985.

FAQUHAR, G. D.; SHARKEY, T. D. Stomatal conductance and photosynthesis. Annual Review of Plant Physiology, Palo Alto, v. 33, p. 317-345, 1982.

FERREIRA, L. G. R. Fisiologia vegetal: relações hídricas. Fortaleza: edições UFC, 1992.131p.

FERRARIO-MÉRY, S. et al. Overexpression of nitrate reductase intobacco delays drought-induced decresses in nitrate reductase activity and mRNA. Plant Physiology, Bethesda, v. 117, p. 283-292, 1998.

GRAHAM, R. D.; ULRICH, A. Potassium deficiency-induced changes in stomatal behavior, leaf water potencials, and root system permeability in Beta vulgaris L. Plant Physiology, Bethesda, v. 49, p. 105109,1972

HAGERMAN, R. H.; HUCKLESBY, D. P. Nitrate reductase from higher plants. In: Methods in enzimology, 1971, 17A, p. 491-503.

HANSON, A. D.; HITZ, W. D.. Methabolic responses of mesophytes to plant water deficits. Annual Review of Plant Physiology, Palo Alto, v. 33, p. 163-203, 1982.

JIAN-KANG ZHU. Plant salt tolerance. Trends in Plant Science - Review. v. 6, n.2, february, 2001.

LACAN, D.; DURAND, M. $\mathrm{Na}^{+}$and $\mathrm{K}^{+}$transport in soybean roots. Physiologia Plantarum, Apenhagem, n. 93, p.132-138, 1995.

LARCHER, W. Ecofisiologia vegetal. 2. ed. São Paulo: EPU, 1987, 319p.

SARRUGE, J. R.; HAAG, H. P. Análise química de plantas. Piracicaba: Escola superior de Agricultura Luiz de Queiroz/USP, 1974, 56p.

SILVEIRA, J. A. G. et al. Alterações no metabolismo do nitrogênio e acumulação de prolina em plantas jovens de cajueiro submetidas a estresse salino. In: CONGRESSO BRASILEIRO DE FRUTICULTURA, 16., 2000, Fortaleza, Anais..., p. 156.

TENHUNEN, J. D.; PEARCY, R. W.AND LANGE, O. L.. Diurnal variations in leaf conductance and gas exchange in natural enviroments, in. 
EDUARDO, Z; FARFUAR, G. D. Stomatal function. California - USA: St University Press, 1987. v.1, cap. 15, p. 323-351.

VENEKAMP, J. H. Regulation of cytosol aciditify in plants under conditions of drought. Physiologia Plantarum, Copenhagen, v. 76, p. 112$117,1989$.

VIÉGAS, R.A.; SILVEIRA, J. A. G. Ammonia assimilation and proline accumulation in Young cashew plants during long term exposure to
NaCl-salinity. Revista Brasileira de Fisiologia Vegetal, Londrina, v. 11, n. 3, p. 131-134, 1999.

VIÉGAS, R.A., MELO, A. R. B.; SILVEIRA, J. A. G.. Nitrate reductase activity and proline accumulation in cashew in response to $\mathrm{NaCl}$ salt shock. Revista Brasileira de Fisiologia Vegetal, Londrina, v. 11, n. 1, p. 21-28, 1999. 